\title{
TUHAN DALAM FITRAH MANUSIA DAN FAKTOR-FAKTOR YANG MERUBAHNYA: KAJIAN TEMATIK AYAT-AYAT DAN HADIS KETAUHIDAN
}

\section{GOD IN HUMAN NATURE AND THE FACTORS THAT CHANGE IT: THE THEMATIC STUDY OF THE SUBJECT AND THE HADITH OF TAUHID}

\author{
Abd. Muqit ${ }^{1}$ \\ Institut Agama Islam (IAI) Faqih Asy'ari Kediri \\ Eko Zulfikar ${ }^{2}$ \\ UIN Raden Fatah Palembang
}

abdmuqit111@gmail.com

\begin{abstract}
ABSTRAK: Tulisan ini berusaha mengupas tentang fitrah manusia dalam bertuhan dan faktor-faktor yang merubahnya sejauh yang dipandang ayat al-Qur'an dan hadis Nabi. Karena penjelasannya mengaitkan ayat al-Qur'an, hadis Nabi, dan penjelasan para ulama terkait suatu tema, maka metode yang digunakan adalah tematik. Dengan demikian, hasil penelitian secara tematisasi menunjukkan bahwa fitrah manusia dalam bertuhan adalah mengimani dan bersaksi atas ketuhanan Allah SWT bahwa Dia Maha Esa. Namun sejak manusia lahir ke dunia, fitrah tersebut dapat berubah disebabkan beberapa faktor, antara lain: (1) faktor nasab atau orang tua; (2) faktor pengaruh setan; (3) faktor keilmuan; (4) faktor mengikuti hawa nafsu; dan (5) faktor takdir. Dari kelima faktor ini, yang pertama, kedua, dan keempat, masih relatif dapat berubah seiring dengan kekuatan dan bertambahnya ilmu pengetahuan agama (baca: faktor ketiga). Sementara faktor kelima tergantung kehendak Allah, karena sudah termaktub sejak zaman azali di mana takdir manusia telah ditetapkan. Kata Kunci: Fitrah Manusia, Faktor Perubahan, Tuhan.
\end{abstract}

ABSTRACT: This paper seeks to explore the nature of human beings in god and the factors that change it as far as the Qur'anic verses and the Prophet's hadith are seen. Because the explanation relates the verses of the Qur'an, the hadith of the Prophet, and the explanations of the scholars regarding a theme, the method used is thematic. Thus, the thematized research results show that human nature in god is to believe in and testify to the divinity of Allah SWT that He is One. However, since humans are born into the world, this nature can change due to several factors, including: (1) factors of lineage or parents; (2) satanic influence factor; (3) scientific factors; (4) the factor of lust; and (5) the fate factor. Of these five factors, the first, second, and fourth, they can still relatively change with the strength and increase of religious knowledge (read: the third factor). Meanwhile, the fifth factor depends on the will of Allah, because it has been contained since ancient times where the destiny of mankind has been determined.

Keyword: Human Nature, Change Factors, God. 


\section{A. PENDAHULUAN}

Telah disepakati bahwa seluruh ayat al-Qur'an khususnya yang turun di Mekah, menjelaskan tentang ajaran tauhid serta mengajak manusia untuk menjauhi kemusyrikan. ${ }^{1}$ Selain ajaran tauhid ini merupakan bentuk manifestasi agar umat manusia selalu berusaha mengesakan Allah, ia juga menjadi salah satu dari maqashid al-syariah (tujuan syariat Islam). ${ }^{2}$ Secara umum, manusia tidak dapat melepaskan diri dari Tuhan yang mengatur alam semesta mulai masa klasik hingga masa yang akan datang, karena ketauhidan disinyalir sebagai salah satu titik penting yang sangat signifikan dalam kehidupan manusia di dunia. ${ }^{3}$

Namun demikian, realitas yang terjadi menunjukkan bahwa masyarakat mulai dari lokal hingga Internasional, telah mempercayai banyak Tuhan yang diajarkan oleh berbagai Agama. Orang Yunani kuno, misalnya, meyakini dan menganut paham politeisme (mempercayai banyak Tuhan): Bintang disebut Tuhan (dewa), Venus disebut Tuhan kecantikan, Mars disebut dewa peperangan, dan Menerva disebut dewa kekayaan, sedangkan Tuhan tertingginya adalah Apolo atau Matahari. Pun juga dengan agama Hindu yang mempercayai dan menganut paham politeisme, yakni meyakini bahwa banyak dewa sebagai Tuhan.

Sebagian masyarakat di Mesir juga ada yang menganut paham Politeisme, mereka mempercayai dewa Iziz, dewi Oziris, dan yang tertinggi adalah dewa Ra'. Sementara masyarakat Arab yang notabene merupakan tempat lahirnya Islam, banyak menyembah berhala-berhala yang diyakini sebagai Tuhan dan menjadi pujaan. ${ }^{4}$ Menurut Ibn Jarir alThabari, selain berbagai Tuhan yang telah dijelaskan di atas, masih banyak Tuhan lainnya yang diyakini oleh manusia, yaitu orang-orang beriman yang mempercayai ketuhanan Allah, orang Yahudi meyakini ketuhanan Allah, orang Shabiin menyembah Malaikat, orang Nashrani meyakini ketuhanan Trinitas, orang Majuzi menyembah matahari, api, dan rembulan, serta kaum musyrikin yang menyembah berhala. ${ }^{5}$

\footnotetext{
${ }^{1}$ M. Quraish Shihab, Sejarah dan Ulum al-Qur'an, (t.tp: Pustaka Firdaus, 2008), h. 11.

2 A. Halil Thahir, Ijtihad Maqasidi, (Yogyakarta: Lkis, 2015), h. 60.

${ }^{3}$ Samidi Khalim, Tuhan, Manusia, dan Alam: Analisis Kitab Primbon Atassadhur Adammakna, Shahih: Journal of Islamicate Multidisciplinary, Vol. 1, No. 1, (2016), h. 16.

${ }^{4}$ M. Quraish Shihab, Wawasan Al-Quran: Tafsir Tematik atas Pelbagai Persoalan Umat, (Bandung: PT. Mizan Pustaka, 2017), h. 20.

${ }^{5}$ Abu Ja'far Muhammad bin Jarir al-Thabari, Jami' al-Bayan 'an Ta'wil Ay al-Qur'an, (Kairo: Dar Hijr, 2001), Juz III, h. 165.
} 
Berbagai keyakinan manusia tersebut sejatinya sangat kontradiktif dengan ajaran Islam, di mana Allah SWT mengutus para Nabi hanya untuk membawa risalah yang wajib mengesakan-Nya (QS. al-Anbiya' [21]: 25). Allah SWT juga menurunkan kitab-kitab suci untuk memberi petunjuk dan pedoman kepada umat manusia agar kembali kepada ajaran tauhid. Oleh karena itu, tidak heran jika sangat banyak ayat-ayat al-Qur'an yang mengecam berbagai kemusyrikan, karena Allah sendiri menciptakan manusia hanya untuk beribadah dan senantiasa mengesakan-Nya. ${ }^{6}$

Secara tegas, al-Qur'an telah menyinggung kepercayaan-kepercayaan manusia di atas dan mengklaim akan diadili sesuai dengan perbuatan yang dilakukannya, sebagaimana penjelasan QS. al-Hajj [22]: 17;

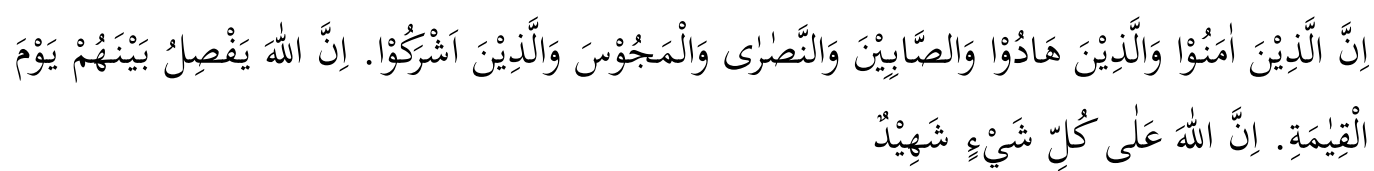

"Sesungguhnya orang-orang beriman, orang Yahudi, orang Shabiin, orang Nashrani, orang Majusi, dan orang musyrik, Allah pasti memberi keputusan di antara mereka pada hari Kiamat. Sungguh, Allah menjadi saksi atas segala sesuatu."

Dari sini tampak jelas, bahwa terdapat ketidak-sesuaian antara keyakinan manusia dalam bertuhan dan ajaran tauhid yang Allah turunkan melalui para Nabi. Hal inilah yang melatar-belakangi penulis untuk meneliti sedikit lebih jauh tentang bagaimana fitrah manusia dalam bertuhan dan faktor-faktor yang merubah mereka dalam menentukan keyakinannya. Tulisan ini diharapkan mampu memberikan wawasan baru terkait konsep Tuhan dalam fitrah manusia, serta menunjukkan bahwa fitrah manusia dalam bertuhan (perspektif Islam) adalah dengan beribadah kepada Tuhan dan senantiasa mengesakanNya.

\section{B. METODE PENELITIAN}

Metode yang digunakan dalam tulisan ini adalah tematik, yakni mengumpulkan dan mengaitkan beberapa ayat al-Qur'an maupun hadis Nabi yang berbicara tentang ketauhidan dengan didukung beberapa referensi lain yang relevan dengan tema yang dibahas. Di samping itu, penulis juga menggunakan studi pustaka (library research)

\footnotetext{
${ }^{6}$ Sa'dullah Affandy, Menyoal Setatus Agama-Agama Pra Islam, (Bandung: PT. Mizan Pustaka, 2015), h. 506.
} 
murni dengan pendekatan deskriptif analitis, yaitu mendeskripsikan dan menafsirkan secara kritis sebuah makna dari setiap pembahasan yang ada sehingga menjadi sebuah gagasan baru.

\section{HASIL DAN PEMBAHASAN}

\section{Konsep Tuhan dalam Al-Qur'an}

Pada umumnya, kata Tuhan digunakan untuk merujuk kepada suatu zat abadi dan supranatural. Dia-lah yang diyakini sebagai Zat Yang Maha Sempurna, pemilik langit dan bumi yang disembah manusia. Menurut Ibn Atsir, Tuhan secara bahasa diartikan pemilik, penguasa, pengatur, pembina, pengurus dan pemberi nikmat. ${ }^{7}$ Dalam Kamus Besar Bahasa Indonesia (KBBI), Tuhan memiliki dua arti penting; pertama: Tuhan diartikan sebagai sesuatu yang diyakini, dipuja, dan disembah oleh manusia sebagai Yang Maha Kuasa, Maha Perkasa, dan sebagainya; kedua, Tuhan diartikan sebagai sesuatu yang dianggap sebagai Tuhan. ${ }^{8}$ Dari kedua definisi ini, tampaknya belum tergambar makna Tuhan secara komprehensif, karena KBBI memang hanya mendefinisikan sesuatu secara umum.

Menurut pandangan al-Ghazali, Tuhan adalah Zat Yang Esa, pencipta alam dan berperan aktif dalam mengendalikan alam. Dia menciptakan alam dari tidak ada menjadi ada. Sementara mukjizat bagi Tuhan merupakan suatu peristiwa yang wajar dan biasa, karena Tuhan mampu mengubah hukum alam yang dianggap tidak bisa berubah menjadi berubah. ${ }^{9}$ Lanjut al-Ghazali, karena Tuhan itu Maha Kuasa dan kehendak-Nya bersifat absolut dan mutlak, maka Dia mampu mengubah segala ciptaan-Nya sesuai dengan kehendak mutlak-Nya. ${ }^{10}$ Sementara dalam literatur Ilmu Tauhid, Tuhan pada umumnya diartikan sebagai Zat yang supranatural namun wujudNya sangat jelas. Dia tidak terbatas waktu, Maha dahulu tanpa awal dan abadi tanpa

\footnotetext{
${ }^{7}$ Iim Fahimah, Tuhan Dalam Perspektif Al-Qur'an, Nuansa: Jurnal Studi Islam dan Kemasyarakatan, Vol. 12, No. 2, (2019): h. 38.

${ }^{8}$ Departemen Pendidikan Nasional, Kamus Besar Bahasa Indonesia, (Jakarta: Pusat Bahasa, 2008), h. 1553.

${ }^{9}$ Fuad Nawawi. Ayat Mukjizat dalam Penafsiran Thabathaba'i dan Muhammad Asad (Pembacaan Hermeneutis Terhadap Tafsir QS. Ali Imran (3): 49). Masile: Jurnal Studi Ilmu Keislaman, Vol. 1, No. 1, (2019): h. 2.

${ }^{10}$ M. Baharudin, Konsepsi Ketuhanan Sepanjang Sejarah Manusia, Al-Adyan: Jurnal Studi Lintas Agama, Vol. 9, No. 1, (2014), h. 35-58.
} 
akhir, Maha sempurna tanpa cacat, pemilik langit dan bumi serta seisinya, oleh karenanya Dialah yang disembah manusia. ${ }^{11}$

Dalam perspektif Islam, Tuhan yang Maha Esa hanyalah Allah SWT. Kata 'Allah' ini menurut sebagian ulama memiliki dua kata serapan; pertama, nama Allah berasal dari kata Wilah, yang berarti ketundukkan, pengagungan, dan penghambaan. Kedua, berasal dari kata Ilah, yang ditambah "al" ma'rifat menjadi al-Ilah. Kemudian alif Ilah-nya dibuang dan menjadi lafadz Allah. Sementara sebagian ulama lain menyimpulkan, bahwa kata Allah tidak memiliki kata serapan. Mereka mengatakan bahwa Allah adalah sebuah Zat wujud yang memiliki seluruh sifat-sifat Ilahiyah. ${ }^{12}$

Tuhan dalam perspektif al-Qur'an diungkapkan dengan dua kata, yakni rabb dan Allah. M. Quraish Shihab mengartikan kata rabb dengan mengarahkannya pada sesuatu menuju kesempurnaan kejadian dan fungsinya secara bertahap. Oleh karena itu, tidak ada satupun kebutuhan makhluk yang tidak disediakan untuk mencapai tujuannya, karena semuanya sudah disediakan oleh Allah. ${ }^{13}$ Dalam Lisan al- 'Arab, kata $r a b b$ diartikan sebagai pembimbing, pengendali, pengatur, dan pemelihara. ${ }^{14}$ Quraish Shihab menambahkan, kata rabb biasa dipakai sebagai salah satu nama Tuhan karena Tuhanlah yang secara hakiki menjadi pemelihara, pendidik, pengasuh, pengatur, dan yang menumbuhkan makhluk-Nya. ${ }^{15}$

Sedangkan kata Allah adalah nama Tuhan yang paling populer. Kata ini terulang dalam al-Qur'an sebanyak 2.698 kali. ${ }^{16}$ Secara tegas Tuhan Yang Maha Esa itu sendiri yang menamai dirinya Allah, sebagaimana ungkapan ayat;

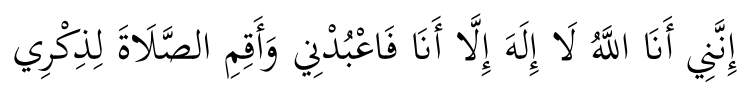

Sesungguhnya Aku ini adalah Allah, tidak ada Tuhan (yang hak) selain Aku. Maka sembahlah Aku dan dirikanlah shalat untuk mengingat Aku. (QS. Thaha [20]: 14).

Kata Allah dalam al-Qur'an memiliki ragam makna, di antaranya ma'bud berarti yang disembah, al-ilahwilah bermakna harapan makhluk, yuwalluhuna bermakna

\footnotetext{
11 Iim Fahimah, Tuhan Dalam Perspektif Al-Qur'an, h. 38.

${ }^{12}$ Muhammad Fakhrudin Al-Razi, Mafatih al-Ghaib, Juz I, (Bairut: Dar al-Ihya', t.th), h. 140.

${ }^{13}$ M. Quraish Shihab, Tafsir al-Mishbah: Pesan, Kesan, dan Keserasian al-Qur'an, Juz II, (Jakarta: Lentera Hati, 2002), h. 86.

${ }^{14}$ Muhammad bin Makram Ibn Mandzur, Lisan al- 'Arab (t.tp: Dar al-Ma'arif, t.th), h. 78.

${ }^{15}$ M. Quraish Shihab, Ensiklopedia al-Qur'an: Kajian Kosa Kata, Juz III, (Jakarta Lentera Hati, 2007), h. 803.

${ }^{16}$ Muhammad Fuad 'Abd al-Baqi, al-Mu'jam al-Mufahras li al-Fadzi al-Qur'an al-Karim, (Beirut: Dar alFikr, t.th), h. 40-75.
} 
merintih dan mengaharap kepada-Nya, ilaha bermakna ibadah atau penyembahan, alaha berartu menakjubkan, dan aliaha ya 'lihu yang berarti tenang. ${ }^{17}$ Kata Allah ini, bagi Quraish Shihab, memiliki kekhususan yang tidak dimiliki oleh kata lain selainNya; ia adalah kata yang sempurna huruf-hurufnya, sempurna maknanya, serta memiliki kekhususan berkaitan dengan rahasianya, sehingga kata tersebut dinamai ismullah al-a'dzam (nama Allah yang paling mulia), yang bila diucapkan dalam doa, Allah akan mengabulkannya. ${ }^{18}$

Dengan demikian dapat dipahami, bahwa kata $r a b b$ lebih mengarah kepada sifat Tuhan, yaitu sebagai pembimbing, pengendali, pendidik, pengasuh, dan pemelihara setiap makhluk yang selalu melibatkan-Nya. Sedangkan makna Allah lebih mengacu pada perilaku makhluk kepada Tuhan, yaitu penyembahan, pengharapan, peribadatan, tempat berharap, serta berdoa. Oleh karena itu, kata Allah lebih istimewa dan populer di kalangan umat Islam, karena memiliki kekhususan dibandingkan kata lainnya yang bermakna Tuhan.

\section{Ketuhanan Allah dalam Fitrah Manusia}

Dari sepanjang lenyapnya ajaran tauhid di muka bumi, Nabi Muhammad kemudian diutus untuk mengajarkan keimanan kepada Allah SWT. Pada masa terjadinya kekosongan ajaran tauhid ini, para ulama sepakat bahwa masa tersebut lazim dinamakan masa fatrah. Terdapat agama Yahudi dan agama Nashrani (baca: agama Samawi) pada masa fatrah, di mana risalah yang dibawa Nabi Musa dan Nabi Isa telah hilang dan dirubah oleh kedua agama tersebut. ${ }^{19}$ Meski demikian, keimanan umat Islam kepada Allah tidak hanya diajarkan lewat para Nabi, Rasul, dan pemuka agama, tetapi sudah menjadi fitrah manusia.

Di dalam al-Qur'an dijelaskan, bahwa manusia pada awal penciptaannya yang berasal dari air mani dan tulang rusuk manusia, telah mengakui dan bersaksi atas ketuhanan Allah, atau -dalam bahasa lain- fitrah manusia adalah beragama Islam, sebagaimana tertulis dalam QS. al-A'raf [7]: 172 berikut ini;

\footnotetext{
${ }^{17}$ Ibn Mandzur, Lisan al- 'Arab., h. 78.

${ }^{18}$ M. Quraish Shihab, Ensiklopedia al-Qur'an., Juz I, h. 77-78.

${ }^{19}$ Affandy, Menyoal Setatus Agama-Agama Pra Islam., h. 98.
} 


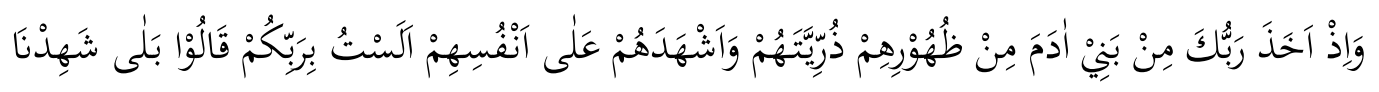

"Dan (ingatlah) ketika Tuhanmu mengeluarkan dari sulbi (tulang belakang) anak сиси Adam keturunan mereka dan Allah mengambil kesaksian terhadap roh mereka (seraya berfirman), "Bukankah Aku ini Tuhanmu?” Mereka menjawab, "Betul (Engkau Tuhan kami), kami bersaksi".

Ayat ini menjelaskan bahwa fitrah manusia mengakui dan bersaksi akan ketuhanan Allah SWT. Fitrah ini kemudian berlanjut hingga manusia dilahirkan dari rahim ibunya. Pengakuan manusia akan fitrahnya ini sebenarnya untuk menyangkal alasan orang-orang yang tidak beriman pada hari kiamat yang mengklaim bahwa mereka orang-orang lalai atau mereka dilahirkan dari orang-orang yang menyekutukan Allah. Oleh karena itu, Allah menegaskan bahwa fitrah manusia mengesakan Allah sudah di-nash saat kerasulan Nabi Muhammad, serta fitrah itu diakui sendiri oleh manusia (QS. al-A'raf [7]: 172-173).

Menurut tafsir Kementerian Agama, Allah menyuruh roh manusia untuk menyaksikan kejadian dirinya yang membuktikan keesaan Allah, keajaiban proses penciptaan manusia dari setetes air sperma hingga menjadi manusia yang bertubuh sempurna serta mempunyai daya tanggap indera, dengan urat nadi dan sistem urat syaraf yang mengagumkan. Setelah itu, Allah menanyakaan kepada roh manusia tersebut: "Bukankah Aku ini Tuhanmu?" Roh manusia menjawab; "Benar, Engkaulah Tuhan kami, kami telah menyaksikan.” Jawaban ini merupakan pengakuan roh pribadi manusia sejak awal kejadiannya akan ketuhanan Allah Yang Maha Esa, serta tidak ada Tuhan lain yang patut disembah kecuali Dia. ${ }^{20}$

Lanjutan dari ayat ini menegaskan, bahwa manusia tidak bisa beralasan lalai pada hari akhir dan mengelak bahwa mereka dilahirkan dari orang musyrik. Ditegaskan dalam QS. al-A'raf [7]: 172-174;

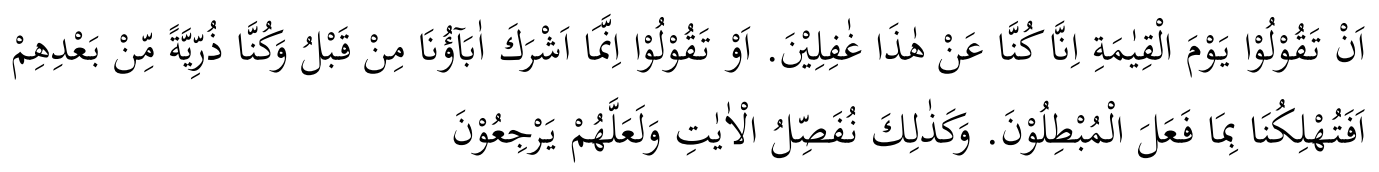

"(Kami lakukan yang demikian itu) agar di hari kiamat kamu tidak mengatakan; "Sesungguhnya ketika itu kami lengah terhadap ini." Atau agar kamu tidak mengatakan, "Sesungguhnya nenek moyang kami telah mempersekutukan Tuhan sejak dahulu, sedang kami adalah keturunan yang (datang) setelah mereka. Maka apakah Engkau akan membinasakan kami karena perbuatan orang-orang

\footnotetext{
${ }^{20}$ Muhammad Thahir Ibn 'Asyur, al-Tahrir wa al-Tanwir, Juz IX, (Tunisia: Dar al-Thunisiayah, 2000), h. 165 .
} 
(dahulu) yang sesat?" Dan demikianlah Kami menjelaskan ayat-ayat itu, agar mereka kembali (kepada kebenaran)."

Dalam membimbing manusia agar beriman, Allah tidak hanya menjadikan fitrah manusia beriman, tetapi keimanan juga diajarkan oleh Allah melalui dakwah para Nabi dan utusan Allah dari masa ke masa. Allah menegaskan bahwa Allah mengutus para Nabi dan rasul hanya untuk mengajarkan keimanan menyembah kepada Allah, sebagaimana terungkap dalam QS. al-Anbiya' [21]: 25 sebagai berikut;

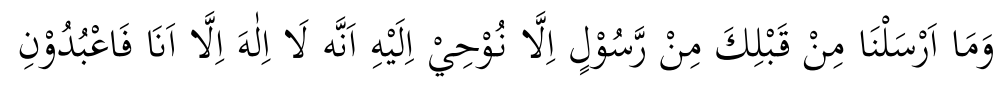

"Dan Kami tidak mengutus seorang rasul pun sebelum engkau (Muhammad), melainkan Kami wahyukan kepadanya, bahwa tidak ada tuhan (yang berhak disembah) selain Aku, maka sembahlah Aku."

Dalam perspektif M. Quraish Shihab, penyampaian ajaran tauhid para rasul kepada umatnya menggunakan metode yang beragam sesuai kondisi dan situasinya dalam kedewasaan berpikir. Nabi Nuh, misalnya, dalam menyampaikan ajaran tauhid tidak mengemukakan bukti-bukti serta argumentatif. Pun juga dengan Nabi Hud yang masanya tidak jauh dari Nabi Nuh, beliau hanya menyuruh selalu mengingat nikmatnikmat Allah yang sudah diberikan kepada mereka sebagai bukti ke-Maha Kuasa-an Allah (QS. al-Syura [26]: 123-140). Sementara pada saat periode Nabi Shalih dan Nabi Syu'aib, ajaran yang disampaikan sudah mulai menggunakan argumentasi bukti-bukti ketuhanan. $^{21}$

Adapun terkait argumentasi-argumentasi dalam ajaran tauhid telah dicontohkan langsung oleh Nabi Ibrahim AS. Hal ini dijelaskan oleh mayoritas ulama bahwa pencarian Tuhan Nabi Ibrahim yang termaktub dalam QS. al-An'am [6]: 76-79, sejatinya bukan gambaran keimanan Nabi Ibrahim, melainkan hanya untuk mengajarkan umat untuk berpikir dalam mencari Tuhan yang logis. Karena tidak mungkin seorang Nabi mengalami kemusyrikan sementara ia memiliki sifat yang ma'shum, yakni terpelihara dari dosa. ${ }^{22}$

Dari uraian di atas dapat pahami, bahwa selain keimanan manusia kepada Allah adalah fitrah, Allah juga sudah mengutus para rusul untuk memerintahkan manusia agar beriman kepada-Nya. Dengan begitu, Allah telah menuntun manusia untuk

\footnotetext{
${ }^{21}$ Shihab, Wawasan Al-Qur'an., h. 28.

${ }^{22}$ Asy'ari Masduki, Islam Moderat, (Kediri: IAIFA Press, 2019), h. 78.
} 
beriman kepada-Nya jauh sebelum manusia lahir di dunia, yakni sejak masih dalam kandungan hingga dewasa. Oleh karena itu, tidak ada alasan logis bagi manusia untuk tidak beriman kepada Allah, karena sejak dari fitrah dan ajaran Allah sudah menuntun manusia untuk senantiasa beriman kepada-Nya.

\section{Faktor-Faktor yang Merubah Fitrah Manusia dalam Bertuhan}

Sebagimana dijelaskan dimuka, bahwa manusia pada awal penciptaannya adalah mengakui Allah sebagai Tuhan, dan itu merupakan fitrah manusia. Meski demikian, orientasi hidup manusia realitasnya banyak yang mengadopsi agama berbeda serta memiliki Tuhan yang berbeda pula. Dalam konteks ini, umat manusia ada yang menuhankan dewa, matahari, bulan, bintang, api, malaikat, nabi, pendeta, alam, tuhan kebaikan dan keburukan, dan bahkan berhala ciptaannya sendiri dijadikan Tuhan. Hal ini beralasan karena terdapat beberapa faktor yang merubah fitrah manusia tersebut, antara lain;

a. Faktor nasab (keturunan)

Faktor nasab atau keturunan ini telah menempati posisi sentral dalam penentuan akidah seseorang, sebagaimana dijelaskan dalam hadis Nabi:

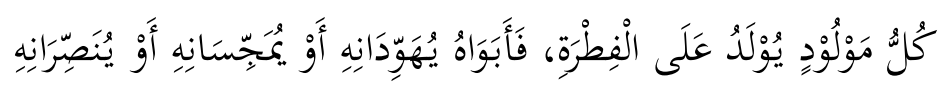

"Setiap anak yang lahir dilahirkan di atas fitrah. Kedua orang tuanyalah yang menjadikannya Yahudi, Majusi, atau Nasrani. "23

Berkaitan dengan hadis ini, terdapat kalimat tambahan dalam riwayat Muslim yang mempertegas maknanya: fain kana muslimaini fa muslim (bila orang tuanya beragama Islam maka anaknya juga beragama Islam). ${ }^{24}$ Penjelasan hadis di atas sejatinya mengindikasikan bahwa munusia dilahirkan dalam keadaaan fitrah, yakni beragama Islam. Namun karena faktor nasab atau kelahiran membuat ia mengadopsi agama yang dianut oleh orang tuanya. Secara realitas, seorang anak yang kebetulan lahir dari keluarga beragama Islam, misalnya, akan terlebih dahulu mengimitasi perilaku orang tuanya yang meyakini bahwa Tuhan hanya satu, yaitu

\footnotetext{
${ }^{23}$ Muhammad bin Ismail Al-Bukhari, Shahih al-Bukhari, Juz II, (t.tp.: Dar Thuq al-Najat, t.th), h. 62.

${ }^{24}$ Abu al-Husain Muslim bin al-Hajjaj al-Naisaburi, Shahih Muslim, (Beirut: Dar al-Afaq al-Jadidah, t.th), Juz VIII, Hadis no: 6932.
} 
Allah. Begitu pula dengan anak yang lahir dari keluarga Kristen, akan melakukan apa saja yang harus dilakukan sebagai seorang Kristen. ${ }^{25}$

Menurut Abu Hasan al-Asy'ari, selain dijelaskan dalam hadis Nabi di atas, keimanan yang disebabkan faktor nasab sebenarnya merupakan taraf iman yang lemah, karena masih tergolong taklid (mengikuti). Namun iman semacam ini bagi al-Asy'ari dan mayoritas ulama dicukupkan, karena akan mengadopsi sepenuhnya perilaku orang tua dalam beragama. Sedangkan dalam pandangan Abu Hasyim, keimanan tersebut belum cukup sampai ia harus belajar dan mencari dalil untuk menguatkan keimanannya. ${ }^{26}$ Maka tidak heran jika dalam menjalani hidup ia berpindah agama, karena selaras dengan bertambahnya ilmu yang dimiliki sehingga mereka berpindah agama sesuai keyakinan pengetahuannya.

b. Faktor pengaruh setan

Dalam suatu hadis qudsi disebutkan, bahwa fitrah manusia sejatinya adalah beragama tauhid, yakni beragama Islam. Namun fitrah tersebut berubah karena pegaruh setan yang pada akhirnya membuat manusia tidak beriman. Disebutkan dalam riwayat Ibn Hibban bahwa;

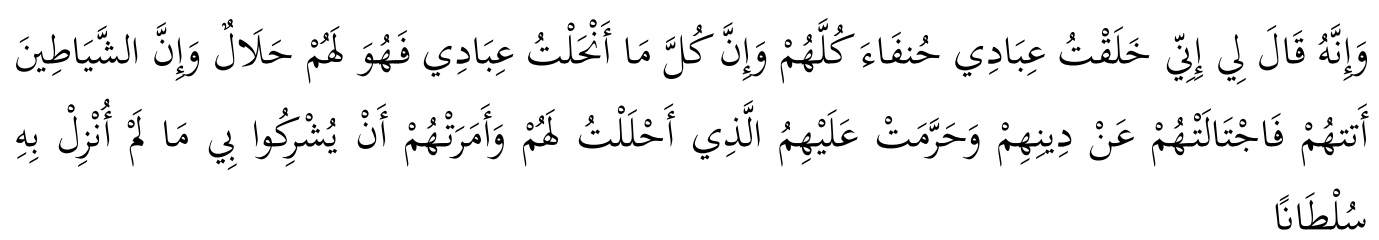

"Allah berfirman: "Sesungguhnya Aku ciptakan hamba-hamba-Ku dengan agama yang lurus. Sesungguhnya setiap sesuatu yang menempat padanya adalah halal baginya. Kemudian datang kepada mereka setan-setan dan memalingkan mereka dari agama (tauhid) mereka, dan setan mengharamkan segala sesuatu yang telah Kuhalalkan bagi mereka, serta setan memerintahkan untuk menyekutukan-Ku."27

Hadis ini secara tegas berbicara tentang penyesatan setan terhadap manusia dari beriman dan mengajaknya untuk menyekutukan Allah. Sudah menjadi kodrat setan untuk menggoda anak-cucu Adam agar selalu menyimpang dari ajaran Islam dan agar kelak menjadi teman kekal-nya di neraka. Pernyataan al-Qur'an juga

25 Eko Zulfikar, Tipologi Hak-Hak Anak Perempuan Dalam Islam: Studi Tematik Hadis-Hadis Keperempuanan, HUMANISMA: Journal Of Gender Studies, Vol. 4, No. 2, (2020), h. 202.

${ }^{26}$ Syamsyuddin, Lawami'u al-Anwar al-Bahiyah, Juz I, (Syiria: Muassisah al-Khafiqin, 1982), h. 37.

${ }^{27}$ Muhammad Ibn Hibban, Shahih Ibn Hibban, Juz II, (Bairut: Muassisah al-Risalah, 1988), 426. 
menegaskan, bahwa setan sudah berikrar untuk selalu menyesatkan manusia dari jalan yang benar, sebagaimana ungkapan QS. al-A'raf [7]: 16-17;

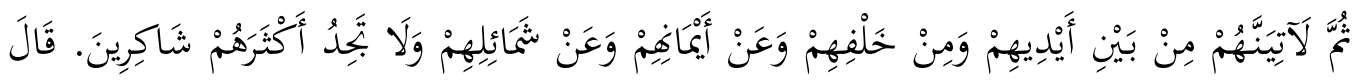

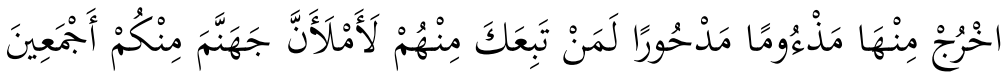

"Iblis menjawab: "Karena Engkau Telah menghukum saya tersesat, saya benar-benar akan (menghalang-halangi) mereka dari jalan Engkau yang lurus. Kemudian saya akan mendatangi mereka dari muka dan dari belakang mereka, dari kanan dan dari kiri mereka. dan Engkau tidak akan mendapati kebanyakan mereka bersyukur (taat)."

Dengan demikian, penolakan terhadap ajaran tauhid yang dibawa Nabi sebenarnya sangat berlawanan dengan fitrah manusia dan suara hati nurani mereka. Karena itu tidaklah benar jika pada hari Kiamat nanti manusia diberi kesempatan untuk mengajukan alasan bahwa mereka alpa, dan tidak pernah diingatkan untuk mengesakan Allah. Justru fitrah manusia sendiri dan ajaran para Nabi senantiasa mengingatkan untuk mengesakan Allah, mentaati seruan Rasulullah, dan menjauhkan diri dari perbuatan syirik kepada Allah SWT.

c. Faktor keilmuan

Secara umum, manusia tidak beragama Islam itu terjadi karena mereka tidak menggunakan potensi akal untuk berpikir kenapa sesuatu yang tidak logis dan tidak memberi manfaat serta mudarat dijadikan Tuhan. Andaikan manusia menggunakan potensi akal untuk berpikir, mereka pasti akan mengetahui dan menemukan Tuhan yang benar, sebagaimana kisah Nabi Ibrahim dalam mencari Tuhan yang diabadikan dalam QS. al-An'am [6]: 76-79 sebagai berikut:

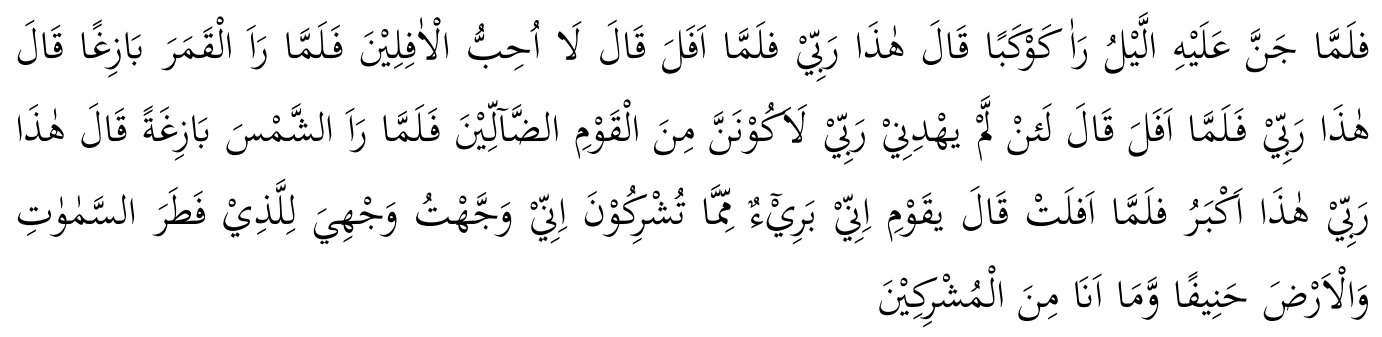

"Ketika malam telah menjadi gelap, dia (Ibrahim) melihat sebuah bintang (lalu) dia berkata; "Inilah Tuhanku." Maka ketika bintang itu terbenam dia berkata, "Aku tidak suka kepada yang terbenam." Lalu ketika dia melihat bulan terbit dia berkata, "Inilah Tuhanku." Tetapi ketika bulan itu terbenam dia berkata, "Sungguh, jika Tuhanku tidak memberi petunjuk kepadaku, pastilah aku termasuk orang-orang yang sesat." Kemudian ketika dia melihat matahari terbit, dia berkata, "Inilah Tuhanku, ini lebih besar." Tetapi ketika 
matahari terbenam, dia berkata, "Wahai kaumku, Sungguh, aku berlepas diri dari apa yang kamu persekutukan." Aku hadapkan wajahku kepada (Allah) yang menciptakan langit dan bumi dengan penuh kepasrahan (mengikuti) agama yang benar, dan aku bukanlah termasuk orang-orang musyrik.

Selain tentang kisah Nabi Ibrahim di atas, al-Qur'an juga mengkisahkan tentang Fir'aun yang pada saat tenggelam mengakui Ketuhanan Allah, padahal sebelumnya ia adalah raja dan medeklarasikan dirinya sebagai Tuhan. Disebutkan dalam QS. Yunus [10]: 90-91;

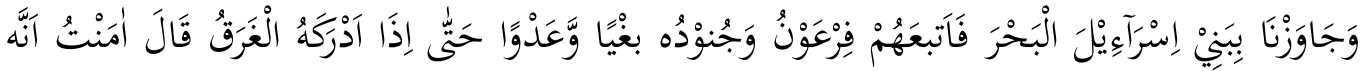

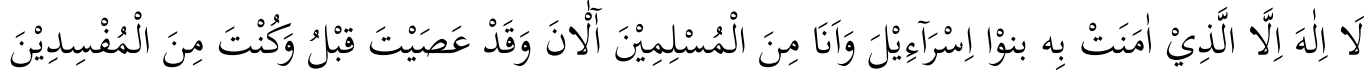

"Dan Kami selamatkan Bani Israil melintasi laut, kemudian Fir'aun dan bala tentaranya mengikuti mereka untuk menzalimi dan menindas (mereka). Sehingga ketika Fir'aun hampir tenggelam dia berkata, "Aku percaya bahwa tidak ada tuhan melainkan Tuhan yang dipercayai oleh Bani Israil, dan aku termasuk orang-orang Muslim. Mengapa baru sekarang (kamu beriman), padahal sesungguhnya engkau telah durhaka sejak dahulu, dan engkau termasuk orang yang berbuat kerusakan."

Di samping kedua kisah di atas, al-Qur'an juga mencoba mengingatkan orang-orang yang tidak beriman dengan dalil-dalil logis, antara lain; Pertama, apakah manusia akan memohon kepada sesuatu selain Allah, sementara ia tidak dapat memberi manfaat dan mengandung mudarat (QS. al-An'am [6]: 71); Kedua, manusia seperti orang dalam keadaan kebingungan yang disesatkan setan di muka bumi (QS. al-An'am [6]: 71); Ketiga, orang-orang yang mereka sembah selain Allah, ia tidak dapat mengabulkan sesuatu-pun bagi mereka, melainkan ia seperti orang yang membukakan kedua telapak tangannya ke dalam air agar air tersebut sampai ke mulutnya (QS. al-Ra'd [13]: 14); Keempat, perumpamaan orang-orang yang mencari pelindung selain Allah adalah seperti laba-laba yang membuat rumah, sedangkan rumah yang paling lemah adalah rumah laba-laba.

Berkaitan dengan dalil-dalil tentang Keesaan Allah, para Teolog sering mengutip dan mengkemukakan QS. al-Anbiya' [21]: 22-24 sebagai berikut;

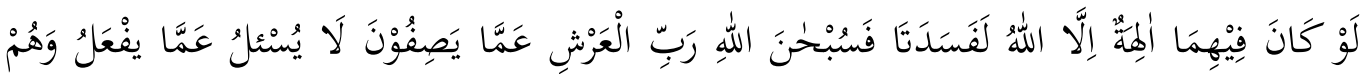

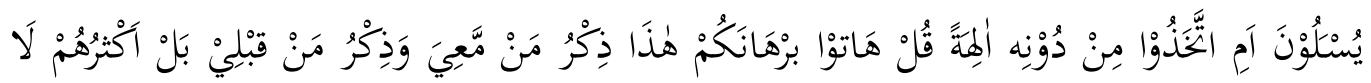

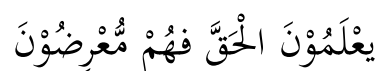


"Seandainya pada keduanya (di langit dan di bumi) ada tuhan-tuhan selain Allah, tentu keduanya telah binasa. Maha Suci Allah yang memiliki 'Arsy dari apa yang mereka sifatkan. Dia (Allah) tidak ditanya tentang apa yang dikerjakan, tetapi merekalah yang akan ditanya. Atau apakah mereka mengambil tuhan-tuhan selain Dia? Katakanlah (Muhammad), "Kemukakanlah alasan-alasanmu! (Al-Qur'an) ini adalah peringatan bagi orang yang bersamaku dan peringatan bagi orang sebelumku." Tetapi kebanyakan mereka tidak mengetahui yang hak (kebenaran), karena itu mereka berpaling."

Pada ayat ini, Allah menegaskan bahwa jika di dunia terdapat banyak Tuhan maka langit dan bumi akan mengalami kerusakan. Pakar Teologi menjelaskan secara logis ayat di atas dengan menganalogikan Tuhan dengan pemimpin. Jika terdapat dualisme otoritas (pemimpin) atau bahkan lebih, maka akan sering menimbulkan dua keputusan yang berbeda. Tentu saja, sesuatu yang dipimpin tidak akan stabil dan mengalami kehancuran manakala dipimpin lebih dari satu orang. Sebagai contoh, satu Tuhan menginginkan matahari terbit dari arah Timur, sementara satu Tuhan lainnya menghendaki matahari terbit dari arah selatan, maka matahari tersebut tidak akan bisa terbit karena saling kontradiktif atau tarik menarik keputusan antara dua Tuhan. ${ }^{28}$

d. Faktor mengikuti hawa nafsu

Faktor lain yang dapat merubah fitrah manusia dalam bertuhan antara lain karena mengikuti hawa nafsu, sebagaimana uraian QS. al-Furqan [25]: 43;

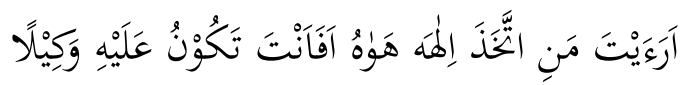

"Sudahkah engkau (Muhammad) melihat orang yang menjadikan keinginannya sebagai tuhannya. Apakah engkau akan menjadi pelindungnya?."

Secara implisit, ayat ini menerangkan sekelompok manusia yang menjadikan hawa nafsunya sebagai Tuhan. Menururt Ibn Jarir al-Thabari, penuhanan terhadap hawa nafsu telah menjadi faktor dibalik penyembahan dan penuhanan terhadap berhala, karena mereka mengikuti hawa nafsunya. Bagi al-Thabari, mereka tak layaknya seperti hewan yang tidak dapat menggunakan akalnya, mereka hanya menuruti hawa nafsunya. ${ }^{29}$ Sementara dalam pandangan Ibnu 'Asyur, penuhanan

\footnotetext{
${ }^{28}$ Husain Afandi, Husun Hamidiyah, (Surabaya: al-Hidayah, 2016), h. 8.

${ }^{29}$ Al-Thabari, Jami' al-Bayan 'an Ta'wil Ay al-Qur'an, Juz XI, h. 297.
} 
hawa nafsu tidak hanya berlaku pada penuhanan berhala, tetapi dapat mencakup penuhanan dan sesembahan apa saja yang didasarkan pada keinginan hawa nafsu. $^{30}$

Dengan demikian, menuruti hawa nafsu merupakan salah satu faktor yang dapat dengan mudah mengubah fitrah manusia dalam bertuhan. Bagi Quraish Shihab, hawa nafsu ini diibaratkan seperti anak kecil, bila ia dibiarkan akan terus menyusu, dan bila dihalangi ia akan berhenti dan terbiasa dengannya. ${ }^{31}$ Oleh karena itu, hawa nafsu akan terus selalu mendorong kepada hal-hal yang bersifat buruk dan mendorong manusia menuju kebinasaan. Apabila seseorang dapat menahan diri dari hawa nafsunya, maka upayanya itu merupakan penangkal sekaligus obat bagi penyakit yang diakibatkan nafsunya.

e. Faktor takdir

Dalam perspektif Islam, manusia tidak beriman kepada Allah bisa terjadi karena memang sudah kehendak Allah SWT, sebagaimana ungakapan QS. Yunus [10]: 99-100 berikut ini;

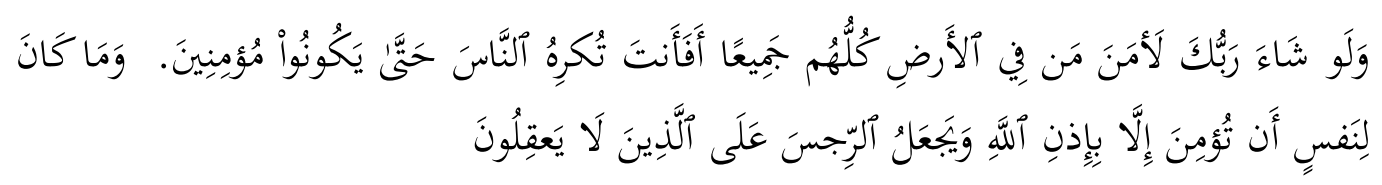

"Dan jikalau Tuhanmu menghendaki, tentulah beriman semua orang yang di muka bumi seluruhnya. Maka apakah kamu (hendak) memaksa manusia supaya mereka menjadi orang-orang yang beriman semuanya. Dan tidak ada seorangpun akan beriman kecuali dengan izin Allah; dan Allah menimpakan kemurkaan kepada orang-orang yang tidak mempergunakan akalnya."

Di dalam kitab tafsirnya, al-Thabari menjelaskan bahwa iman manusia di muka bumi adalah kehendak Allah SWT. Jika Allah menghendaki beriman maka semua penduduk bumi tentu akan beriman, dan membenarkan ajaran yang dibawa Rasululllah. Menolaknya mereka terhadap risalah yang dibawa Nabi karena sudah takdir sejak zaman azali, mereka tidak beriman, tidak mengikuti, dan tidak membenarkan kerasulan Nabi Muhammad SAW. ${ }^{32}$

Ibnu Abbas sebagaimana dikutip oleh Muhammad Yasir mengemukakan, bahwa ayat di atas dan ayat semacamnya merupakan informasi dari Allah untuk

\footnotetext{
${ }^{30}$ Thahir Ibn 'Asyur, al-Tahrir wa al-Tanwir, Juz IX, h. 198.

${ }^{31}$ Shihab, Tafsir al-Mishbah., Juz XV, h. 49.

${ }^{32}$ Al-Thabari, Jami' al-Bayan 'an Ta'wil Ay al-Qur'an, Juz XI, 297.
} 
Nabi Muhammad karena telah senang melihat semua manusia beriman dan mengikuti ajarannya. Dengan demikian, Allah menurunkan ayat tersebut dan semacamnya sebagai penjelasan bahwa mereka tidak akan beriman karena ditakdirkan baik. Begitu sebaliknya, seseorang tidak tersesat karena dia oleh Allah tidak ditakdirkan celaka. ${ }^{33}$

Dari penjelasan faktor-faktor di atas, dapat dipahami bahwa faktor yang ketigalah yang paling kuat dalam merubah fitrah manusia dalam bertuhan, karena keimanannya dilandasi dengan keilmuan dan dalil-dalil objektif. Sedangkan untuk faktor pertama, kedua, dan keempat, masih bertaraf rendah dan labil, dimungkinkan sangat mudah berubah karena masih taqlid serta tidak berdasarkan pada keilmuannya. Dengan demikian, para ulama menghukumi fardu kifayah untuk menyampaikan ajaran-ajaran Islam beserta dalilnya, baik dalil naqli atau aqli (logis). ${ }^{34}$ Selain itu, umat Islam juga tidak diperkenankan memaksakan umat agama lain untuk manganut agama Islam, kewajibannya hanya menyampaikan ajaran tanpa ada paksaan. Sebagai contoh, menjelaskan bahwa Islam adalah agama yang logis, faktual, ajarannya paling sempurna, serta memiliki kitab suci otentik. ${ }^{35}$

\section{SIMPULAN}

Dari uraian yang relatif singkat di atas, dapat disimpulkan bahwa: fitrah manusia hidup di dunia adalah mengimani dan bersaksi atas ketuhanan Allah SWT bahwa Dia Maha Esa. Hal ini terjadi sejak terpisahnya air sperma dari tulang rusuk kedua orang tua, dan terus berlangsung hingga manusia dilahirkan dari rahim ibunya. Kemudian ketika manusia lahir ke dunia, fitrah itu mulai dipengaruhi oleh berbagai faktor yang dapat menyebabkan manusia memilih Tuhan tertentu sesuai agama yang diyakininya. Paling tidak ada lima faktor yang mempengaruhi fitrah manusia dalam bertuhan, antara lain: (1) faktor nasab atau orang tua; (2) faktor pengaruh setan; (3) faktor keilmuan; (4) faktor mengikuti hawa nafsu; dan (5) faktor takdir. Dari kelima faktor tersebut, yang pertama, kedua, dan keempat, masih relatif dapat berubah seiring dengan kekuatan dan bertambahnya ilmu pengetahuan agama (baca: faktor ketiga). Sementara faktor kelima

\footnotetext{
${ }^{33}$ Muhammad Yasir, Makna Toleransi dalam Al-Quran, Jurnal Ushuluddin, Vol. 22, No. 2, (2014), h. 18. ${ }^{34}$ Zainuddin, Fathul Muin, (Jakarta: Dar al-Kutub al-'Alamiah, 2000), h. 78.

${ }^{35}$ Abd. Muqit, Harmonisasi Antar Umat Beragama Dalam Negara Multi Agama Dalam Perspektif AlQuran, Ta'wiluna: Jurnal Ilmu Al-Qur'an, Tafsir, dan Pemikiran Islam, Vol. 1, No. 1, (2020): h. 41-58.
} 
tergantung kehendak Allah, karena sudah termaktub sejak zaman azali di mana takdir manusia telah ditetapkan.

\section{DAFTAR PUSTAKA}

Affandy, Sa'dullah. Menyoal Setatus Agama-Agama Pra Islam. Bandung: PT. Mizan Pustaka, 2015.

Afandi, Husain. Husun Hamidiyah. Surabaya: al-Hidayah, 2016.

Al-Baqi, Muhammad Fuad 'Abd. al-Mu'jam al-Mufahras li al-Fadzi al-Qur'an alKarim. Beirut: Dar al-Fikr, t.th.

Al-Bukhari, Muhammad bin Ismail. Shahih al-Bukhari. t.tp.: Dar Thuq al-Najat, t.th.

Al-Naisaburi, Abu al-Husain Muslim bin al-Hajjaj. Shahih Muslim, Beirut: Dar al-Afaq al-Jadidah, t.th.

Al-Razi, Muhammad Fakhrudin. Mafatih al-Ghaib. Bairut: Dar al-Ihya', tt.h.

Al-Thabari, Abu Ja'far Muhammad bin Jarir. Jami' al-Bayan 'an Ta'wil Ay al-Qur'an. Kairo: Dar Hijr, 2001.

Al-Zuhaili, Wabah bin Mushtafa. Tafsir al-Wasith. Bairut: Dar al-Fikr, 2000.

Baharudin, M. Konsepsi Ketuhanan Sepanjang Sejarah Manusia. Al-Adyan: Jurnal Studi Lintas Agama, Vol. 9, No. 1, 2014.

Departemen Pendidikan Nasional. Kamus Besar Bahasa Indonesia. Jakarta: Pusat Bahasa, 2008.

Dzulhadi, Qosim Nursheha. Al-Qur'an dan Pengembangan Studi Agama (Telaah terhadap Yahudi, Kristen, Sabea, dan Majusi). Jurnal Tsaqafah, Vol. 10, No. 2, 2014

Fahimah, Iim. Tuhan Dalam Perspektif Al-Qur'an. Nuansa: Jurnal Studi Islam dan Kemasyarakatan, Vol. 12, No. 2, 2019.

Fuad Nawawi. Ayat Mukjizat dalam Penafsiran Thabathaba'i dan Muhammad Asad (Pembacaan Hermeneutis Terhadap Tafsir QS. Ali Imran (3): 49). Masile: Jurnal Studi Ilmu Keislaman, Vol. 1, No. 1, (2019).

Ibn 'Asyur, Muhammad Thahir. al-Tahrir wa al-Tanwir. Tunisia: Dar al-Thunisiayah, 2000.

Ibn Hibban, Muhammad. Shahih Ibn Hibban. Bairut: Muassisah al-Risalah, 1988.

Ibn Mandzur, Muhammad bin Makram. Lisan al-'Arab. t.tp: Dar al-Ma'arif, t.th. 
Khalim, Samidi. Tuhan, Manusia, dan Alam: Analisis Kitab Primbon Atassadhur Adammakna. Shahih: Journal of Islamicate Multidisciplinary, Vol. 1, No. 1, 2016. Masduki, Asy’ari. Islam Moderat. Kediri: IAIFA Press, 2019.

Muqit, Abd. Harmonisasi Antar Umat Beragama Dalam Negara Multi Agama Dalam Perspektif Al-Quran. Ta'wiluna: Jurnal Ilmu Al-Qur'an, Tafsir, dan Pemikiran Islam, Vol. 1, No. 1, 2020.

Shihab, M. Quraish. Wawasan Al-Quran: Tafsir Tematik atas Pelbagai Persoalan Umat. Bandung: PT. Mizan Pustaka, 2017.

- Tafsir al-Mishbah: Pesan, Kesan, dan Keserasian al-Qur'an. Jakarta: Lentera Hati, 2002.

---------------. Ensiklopedia al-Qur'an: Kajian Kosa Kata. Jakarta Lentera Hati, 2007.

-----------------. Membaca Sirah Nabi Muhammad SAW Dalam Sorotan Al-Qur'an dan Hadits-Hadits Shahih. Jakarta: Lentera Hati, 2012. Sejarah dan Ulum al-Qur'an. t.tp: Pustaka Firdaus, 2008.

Syafieh. Tuhan dalam Perspektif al-Qur'an. At-Tibyan: Jurnal Ilmu Al-Qur'an dan Tafsir, Vol. 1, No. 1, 2016.

Syamsyuddin. Lawami'u al-Anwar al-Bahiyah. Syiria: Muassisah al-Khafiqin, 1982.

Thahir, A. Halil. Ijtihad Maqasidi. Yogyakarta: Lkis, 2015.

Urrozi, Khoirun Nisa. Agama Majusi Dalam Tinjauan Hadis. Religious: Jurnal Studi Agama-Agama dan Lintas Budaya, Vol. 3, No. 2, 2019.

Yasir, Muhammad. Makna Toleransi dalam Al-Quran. Jurnal Ushuluddin, Vol. 22, No. 2,2014

Zainuddin. Fathul Muin. Jakarta: Dar al-Kutub al-'Alamiah, 2000.

Zulfikar, Eko. Tipologi Hak-Hak Anak Perempuan Dalam Islam: Studi Tematik HadisHadis Keperempuanan, HUMANISMA: Journal Of Gender Studies, Vol. 4, No. 2,2020 . 